\title{
甲壳动物横纹肌肌原纤维副肌球蛋白 的分离和结晶*
}

\author{
韩永根陈明 \\ （中国科学院上海生理研究所）
}

自从 Bear ${ }^{[1]}$ 在软体动物平滑肌中发现副肌球蛋白之后, Bailey ${ }^{[2]}$ 从牡蚛闭壳肌中分离并 结晶了这种蛋白, 称它为“不溶性”原肌球蛋白. 在相当长的时期中, 普遍认为它是软体动物肌 内的主要收缩蛋白成分, 以为它与软体动物的 catch 型肌肉的持续维持张力而极少消耗能量的 收缩特性密切相关. 然而, de Villafranca 和 Leitner（1967）以及 Ikemoto 和 Kawaguti (1967) 在當横纹肌中鉴定出副肌球蛋白以后, 许多实验资料表明副肌球蛋白广泛分布于无脊椎动物 直至脊索动物的尾索类和头索类动物中 ${ }^{[3-6]}$. 对于甲壳动物横纹肌, 应用 Bailey ${ }^{[2]}$ 或者 Bullard 等 ${ }^{[3]}$ 方法往往不能得到纯的副肌球蛋白. 我们适当改变透析条件, 从沼虾、对虾腹届肌中获得 了纯的副肌球蛋白类晶体.

\section{方法}

以沼虾 (Macrobrochium nipponenois) 和对虾 (Peuaeus oriensalis) 腹屈肌为材料, 将新鲜 的虾腹屈肌放人 $\mathrm{pH} 7.0$ 的低离子强度盐溶液中, 经匀浆、反复摚拌浸洗和低速离心以纯化肌原 纤维. 继以酒精和乙醚处理肌原纤维得干粉. 取一定量的肌原纤维干粉用高离子强度盐溶液 抽提, 将抽提液对 $\mathrm{pH} 6.0$ 、离子强度近于 0.3 的盐溶液透析, 使副肌球蛋白的类晶体析出. 蛋白 质的 SDS-聚丙烯酰胺胶电泳按 Porzio 方法进行 ${ }^{[0]}$, 类晶体的电子显微镜观察同前文 ${ }^{[g]}$.

\section{结果与 讨 论}

副肌球蛋白在中性和微碱性时,易溶于高离子强度溶液中, 而在微酸性时, 经低离子强度 溶液透析, 可呈类晶体析出. 然而, 在甲壳动物肌肉中,由于其原肌球蛋白的溶解度较为特殊, 在低离子强度时溶解度较低, 若按 Bailey ${ }^{[2]}$ 以及 Bullard 等 ${ }^{[3]}$ 方法, 则不能得到纯的甲壳动物 副肌球蛋白. 因此, 我们改变结晶条件, 将结晶时溶液的离子强度从 0.1 提高到 0.3 , 经重结晶 3-4 次, 这样就使副肌球蛋白与原肌球蛋白完全分离, 从而获得了纯度高的副肌球蛋白. 经 SDS-聚丙烯酰胺凝胶电泳,显示出清晰的副肌球蛋白峰. 图 $1 \mathrm{a} 、 \mathrm{~b}$ 分别为对虾和沼虾副肌球蛋 白凝胶电泳扫描. 用电子显微镜观察对虾和沼虾副肌球蛋白类晶体, 均呈针状 (图 2a、b). 高 倍放大时可见到横纹结构, 对虾副肌球蛋白类晶体具有 $14.5 \mathrm{~nm}$ 和 $72.5 \mathrm{~nm}$ 周期(图 $3 \mathrm{a} 、 \mathrm{~b}$ ). 沼 虾副肌球蛋白类晶体具有 $14.5 \mathrm{~nm}$ 周期(图 4).

现有不少实验资料表明副肌球蛋白既存在于持续收缩型肌肉, 也存在于快速收缩型肌肉, 它提示了副肌球蛋白有如下几点功能:（1)副肌球蛋白是肌肉粗丝的中芯部分, 可能有影响或

* 王宝华同志参加技术工作. 

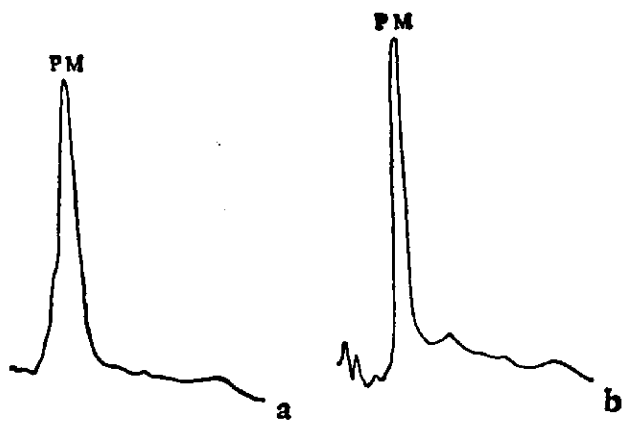

图 1 对虾(a)、沼虾(b)副肌球㔻白

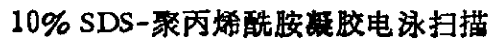

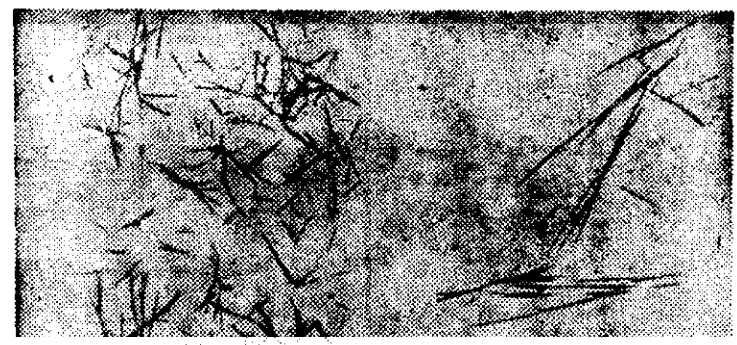

图 2 对虾(a)、沼虾(b)副肌球蛋白类晶体， 醋酸铀负染, 呈针状 $(\times 2750)$

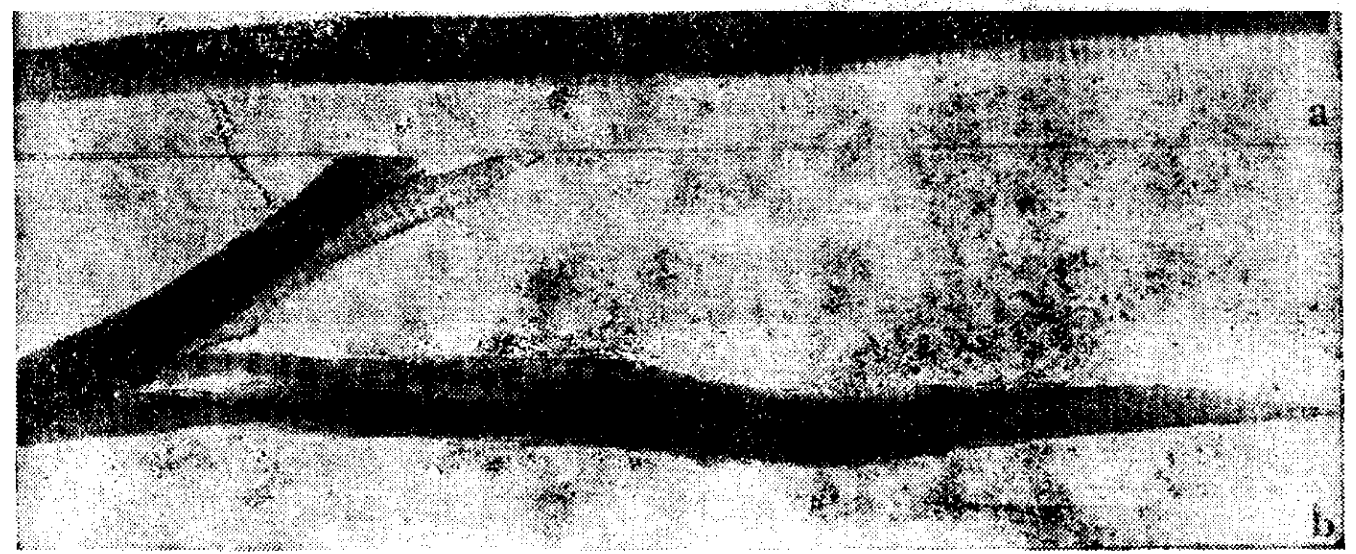

图 3 对虾副肌球蛋白类晶体,醋酸铀负染图

a. 呈现出横纹周期为 $14.5 \mathrm{~nm}(\times 55000) ; b$. 呈现出横纹周期为 $72.5 \mathrm{~nm}(\times 55000)$

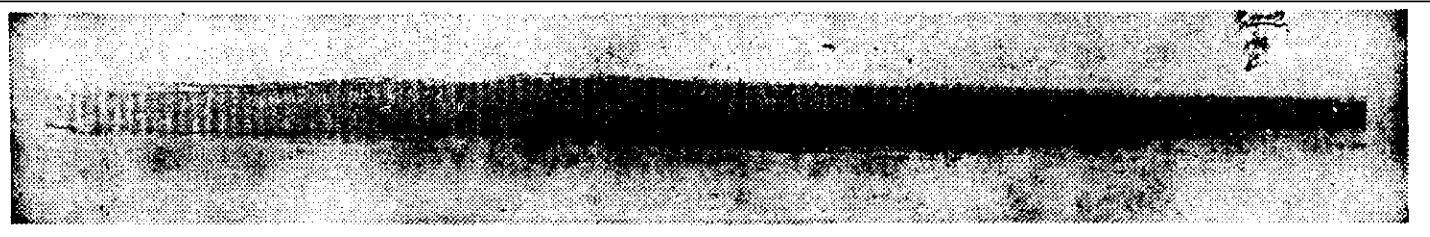

图 4 溜虾副肌球蛋白类晶体,䤑酸铀负染,呈现出横纹周期为 $14.5 \mathrm{~nm}(\times 50000)$

控制肌球蛋白丝长度的作用; (2)由蛤闭壳肌得到的副肌球蛋白在一定条件下,能㧕制需链的、 肌动蛋白激活的蛤闭壳肌和兔骨骼肌肌球蛋白 ATP 酶的活性;(3)副肌球蛋白、肌动蛋白在与 肌球蛋白的作用时有竞争作用. 副肌球蛋白在肌肉中的生理功能是一值得深入探讨的课题.

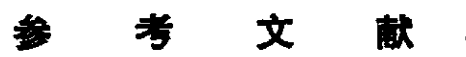

[1] Bear, R. S., J. Am. Chem. Soc., 66(1944), 2043-2050.

[ 2 ] Bailey, K. and Rilegg, J. C., Biochim. Biophys. Acta, 38(1960), 239-245.

[ 3 ] Bullard, B., Hammond, K. S. and Luke, B. M., J. Mol. Biol., 115 (1977), 417-440.

[4] 邹氷水、沈获英,科学通报, 24(1979)，13: 615-616.

[ 5 ] 获明、范世蓝,生物化学与生物物理学报, 14(1982), 94-96.

[ 6 ] Chen Ming, Zhou Nianhui and Fan Shihfang, Materials Science and Biology, Science. Press, Beijing, 1982, 223-226.

[ 7 ] Porzio, M. A. and Pearson, A. M., B. B. A., 490(1977), $27-34$.

第 23 期

科 学 通 报 